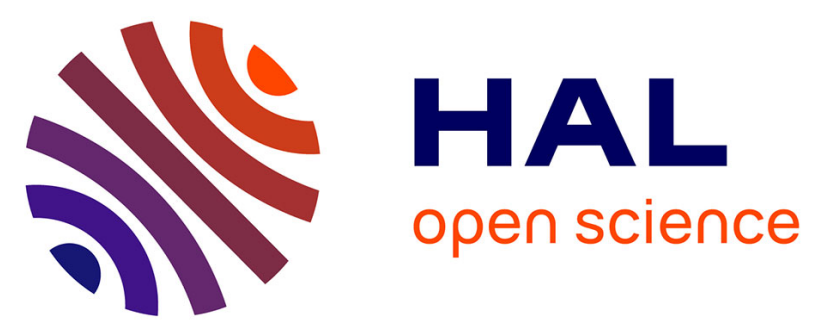

\title{
Decrease of memory retention in a parasitic wasp: an effect of host manipulation by Wolbachia?
}

\author{
Hossein Kishani Farahani, Ahmad Ashouri, Seyed Hossein Goldansaz, Martin
}

S. Shapiro, Jean-Sébastien Pierre, Joan van Baaren

\section{To cite this version:}

Hossein Kishani Farahani, Ahmad Ashouri, Seyed Hossein Goldansaz, Martin S. Shapiro, JeanSébastien Pierre, et al.. Decrease of memory retention in a parasitic wasp: an effect of host manipulation by Wolbachia?. Insect Science, 2017, 24 (4), pp.569-583. 10.1111/1744-7917.12348 . hal01305485

\section{HAL Id: hal-01305485}

\section{https://hal-univ-rennes1.archives-ouvertes.fr/hal-01305485}

Submitted on 21 Jun 2016

HAL is a multi-disciplinary open access archive for the deposit and dissemination of scientific research documents, whether they are published or not. The documents may come from teaching and research institutions in France or abroad, or from public or private research centers.
L'archive ouverte pluridisciplinaire HAL, est destinée au dépôt et à la diffusion de documents scientifiques de niveau recherche, publiés ou non, émanant des établissements d'enseignement et de recherche français ou étrangers, des laboratoires publics ou privés. 
Author running head: H. K. Farahani et al.

Title running head: Memory retention manipulation by Wolbachia

Correspondence: Hossein Kishani Farahani, Department of Plant Protection, Faculty of Agriculture and Natural Resources, University of Tehran, PO Box 4111, Karaj, Iran

\title{
ORIGINAL ARTICLE
}

\section{Decrease of memory retention in a parasitic wasp: an effect of host manipulation by}

\section{Wolbachia?}

Hossein Kishani Farahani ${ }^{1}$, Ahmad Ashouri ${ }^{1}$, Seyed Hossein Goldansaz ${ }^{1}$, Martin S. Shapiro ${ }^{2}$, Jean-Sebastien Pierre ${ }^{3}$ and Joan van Baaren ${ }^{3}$

${ }^{1}$ Department of Plant Protection, Faculty of Agriculture and Natural Resources, University of Tehran, Karaj, Iran; ${ }^{2}$ Department of Psychology, California State University, Fresno, USA; ${ }^{3}$ University of Rennes 1, UMR-CNRS 6553 EcoBio, Avenue du Général Leclerc, Campus de Beaulieu, 35042 Rennes Cedex, France.

\begin{abstract}
Several factors, such as cold exposure, aging, the number of experiences and viral infection, have been shown to affect learning ability in different organisms. Wolbachia has been found worldwide as an arthropod parasite/mutualist symbiont in a wide range of species, including insects. Differing effects have been identified on physiology and behavior by Wolbachia. However, the effect of Wolbachia infection on the learning ability of their host had never previously been studied. The current study carried out to compare learning ability and memory duration in two strains of the parasitoid Trichogramma brassicae: one uninfected
\end{abstract}


and one infected by Wolbachia. Both strains were able to associate the novel odors with the reward of an oviposition into a host egg. However, the percentage of females that responded to the experimental design and displayed an ability to learn in these conditions was higher in the uninfected strain. Memory duration was longer in uninfected wasps $(23.8 \mathrm{~h}$ and $21.4 \mathrm{~h}$ after conditioning with peppermint and lemon, respectively) than in infected wasps (18.9 $\mathrm{h}$ and $16.2 \mathrm{~h}$ after conditioning with peppermint and lemon, respectively). Memory retention increased in response to the number of conditioning sessions in both strains, but memory retention was always shorter in the infected wasps than in the uninfected ones. Wolbachia infection may select for reduced memory retention because shorter memory induces infected wasps to disperse in new environments and avoid competition with uninfected wasps by forgetting cues related to previously visited environments, thus increasing transmission of Wolbachia in new environments.

Key words associative learning; memory duration; spacing learning; Trichgramma brassicae; Wolbachia infection

\section{Introduction}

Learning is widespread throughout the animal kingdom and plays a central role in adapting to local spatial and temporal environmental conditions (Ardiel \& Rankin, 2010; Pravosudov \& Smulders, 2010; Mery, 2013). Learning occurs throughout an animal's lifetime, impacting all aspects of life, for example, from searching for a mate, locating and choosing resources, and identifying predators or conspecifics (van Baaren et al., 2005, Dukas, 2003, 2008a; Giunti et al., 2015). The acquisition of information plays a critical role in predicting future conditions and therefore needs to be stored and retrieved in the memory.

Although it is generally assumed that learning is beneficial, direct measurements of the benefits of learning and memory in terms of fitness reveal that learning and memory may also 
be costly (Dukas \& Bernays, 2000; Dukas, 2008b; Raine \& Chittka, 2008). Tradeoffs can therefore be expected between the importance of memory for fitness gains and the energy consumed for the production, consolidation, or retention of memory. In various species, the retention of memory ranges from a few seconds to several years (Rankin et al., 1990; Portavella et al., 2004; Giurfa, 2007; Giurfa \& Sandoz, 2012; Bruck, 2013). This duration is determined by numerous factors such as the number of training sessions (Toppino \& Bloom, 2002), diet (Suzuki et al., 1998; Petursdottir et al., 2008), aging (Gallagher \& Rapp, 1997; Page \& Peng, 2001; Schaie et al., 2004; Weiler et al., 2008; Bartolo et al., 2010), stress (Nishio et al., 2001; Shors, 2004), reward intensity and value (Adcock et al., 2006; Hoedjes et al., 2010; Kruidhof et al., 2012), or cold exposure (van Baaren et al., 2006). External biotic factors such as viruses, bacteria, and fungi can also affect the learning ability of animals. The influence of parasitic infections on cognitive functions has undergone considerable study in vertebrates (Kavaliers \& Colwell, 1995; Kavaliers et al., 1995; Braithwaite et al., 1998; Cox \& Holland, 2001), but has received less attention in the invertebrates (Gegear et al., 2006; Iqbal \& Mueller, 2007; Kralj et al., 2007). However, in invertebrates, parasitic infections can have detrimental effects on cognition. For example, the use of floral information was impaired in bumblebees [Bombus impatiens Cresson (Hymenoptera: Apidae)] infected with the gut protozoan parasite Crithidia bombi Lipa and Triggiani (Kinetoplastida: Trypanosomatidae) (Gegear et al., 2006). In addition, adult honey bees [Apis mellifera L. (Hymenoptera: Apidae)] infected with Varroa destructor Anderson and Trueman (Parasitifomres: Varroidae) displayed a reduced learning capacity (Kralj et al., 2007) and lower rates of return to their colony, possibly due to a loss of learning and cognition (Kralj \& Fuchs, 2006). 
The number of learning experiences during an animal's lifetime may affect memory duration (Roitberg, 1993; Pearce, 2008). A range of animals have been studied (Apis mellifera, Drosophila, the marine mollusks Aplysia and Hermissenda, rats and rabbits) with regard to the effects of repeated experience on memory formation (Carew et al., 1972; Fanselow \& Tighe, 1988; Tully et al., 1994; Spieler \& Balota, 1996; Kogan et al., 1997; Hermitte et al., 1999; Muzzio et al., 1999; Beck et al., 2000; Wu et al., 2001). Honeybees (Apis mellifera) have been successfully used to describe the dynamics of memory formation after single or multiple-trial appetitive learning both in color learning by free-flying bees and in olfactory proboscis extension conditioning (Menzel \& Müller, 1996; Menzel, 1999; Giurfa, 2007; Giurfa \& Sandoz, 2012), indicating that a consolidation process occurs within a few minutes after learning. In all cases, multiple learning trials facilitate memory consolidation into long lasting memories extending over one or several days.

Wolbachia is an $\alpha$-proteobacteria living as an obligatory endosymbiont (Taylor \& Hoerauf, 1999) and has been found in numerous arthropod species, including spiders, terrestrial isopods, such as filarial nematodes, mites, and insects (Goodacre et al., 2006; Werren et al., 2008; Cordaux et al., 2012). In arthropods, Wolbachia has evolved a large number of strategies to manipulate host reproduction including parthenogenesis induction, feminization, and male killing to enhance its transmission (Werren et al., 2008). Up to $10 \%$ of species of parasitoids belonging to the Trichogramma genus are known to be infected with Wolbachia in which it induced thelytokous forms (Poorjavad et al. 2012). Species belonging to the Trichogramma genus are endoparasitoids, and most species are associated with eggs of Lepidoptera, although some can also attack dipteran, coleopteran, and symphytan eggs (Hoffmann et al., 1995; Pinto, 1998b; Mansfield \& Mills, 2002). Trichogramma brassicae (Westwood) is a biological control agent that is widely used against various pest species. In 
nature, one uninfected and one infected strain of $T$. brassicae coexist with the infected strain only producing female offspring (Farrokhi et al., 2010; Poorjavad et al., 2012).

Most of the studies have focused on the effects of Wolbachia infection on arthropod traits such as fecundity, longevity, adult size, parasitism rates, and the rate of emergence of Wolbachia-infected wasps (Hohmann et al., 2001; Grenier \& De Clercq, 2003; Miura \& Tagami, 2004). Wolbachia affects several life history traits in some species, either in a way that increases its transmission (Silva et al., 2000; Hohmann et al., 2001; Zchori-Fein et al., 2001; Panteleev et al., 2007) or negatively due to side-effects of Wolbachia infection (Fialho \& Stevens, 2000; Weeks et al., 2007). In the strains studied in this paper, we have shown that Wolbachia infection can impair the decision-making process during patch exploitation, potentially increasing transmission, but at the expense of a decrease of fitness of the infected individuals (Kishani Farahani et al., 2015). Here we investigated the influence of Wolbachia infection on three experience-dependent behaviors: (i) the ability to learn; (ii) the ability to retain memory and (iii) the effect of additional experience on memory retention. The main methodology is a Pavlovian conditioning assay in which female parasitic wasps associate the reward (a host) with an odor, using a flight chamber to observe the response of $T$. brassicae after conditioning.

\section{Material and methods}

Parasitoids

In this paper, we compare two strains of T. brassicae: one that is Wolbachia infected and one that is not (uninfected). Both strains came from cultures maintained by the Biological Control Research Department (BCRD) of the Iranian Research Institute of Plant Protection (IRIPP). The original source of these parasitoids were collected from north Iran (Baboulsar 
Region, South of Caspian Sea) in the same fields in 2012. The current study was conducted on two naturally infected and uninfected wasp populations. It has been shown that these strains have the same genetic background and thus all observed difference will be due to Wolbachia prevalence (Kishani Farahani et al. 2015). In many comparative studies investigating the effects of Wolbachia between stains, uninfected strains are produced via antibiotic treatment to an infected strain. However, there is evidence to suggest that such antibiotic treatment may have negative effects on Wolbachia treated arthropods (Timmermans and Ellers 2009; Dedeine et al. 2001) impacting both physiology and behavior. As such, the possibility that observed differences are due to a negative effect of antibiotic treatment could not be ruled out.

Genetic similarity was performed based on the size of the nuclear ribosomal DNA (nrDNA) internal transcribed spacer 2 (ITS-2) region amplified through PCR. The sequences were aligned and then subjected to a maximum parsimony analysis (with MEGA5 software), with heuristic search and TBR branch-swapping algorithm, in order to phylogenetically assess the identification and common origin of our strains (Kishani Farahani et al., 2015).

In our infected strain, Wolbachia prevalence was determined in female wasps which produced only female offspring (Huigens \& Stouthamer, 2003). Wolbachia presence was verified by a PCR method based on the Wolbachia surface protein (wsp) (81F/691R primers; Braig et al., 1998). PCR-reactions were performed as described for Trichogramma species identification with the following two modifications: (1) the primers used to amplify the $w s p$ region were 5'-TGGTCCAATAAGTGATGAAGAAAC-3' (forward) and $5^{\prime}$ AAAAATTAAACGCTACTCCA-3' (reverse), and (2) the cycling program was: 3 min at $94{ }^{\circ} \mathrm{C}, 40$ cycles of $1 \mathrm{~min}$ at $94{ }^{\circ} \mathrm{C}, 1 \mathrm{~min}$ at $50{ }^{\circ} \mathrm{C}$ and $1 \mathrm{~min}$ at $72{ }^{\circ} \mathrm{C}$, followed by $5 \mathrm{~min}$ at $72{ }^{\circ} \mathrm{C}$ after the last cycle (Braig et al., 1998). The Wolbachia infected line was monitored 
throughout the experimental duration by PCR tests to ensure that all different behaviors were due to Wolbachia presence. All female wasps which produce only female progeny were proved to be infected by Wolbachia.

Parasitoids were reared at $25 \pm 1{ }^{\circ} \mathrm{C}, 50 \% \pm 5 \% \mathrm{RH}$ and $16: 8 \mathrm{~L}: \mathrm{D}$ on eggs of Ephestia kuehniella Zeller (Lepidoptera: Pyralidae). E. kuehniella eggs were used in the following experiments for both infected and uninfected wasps. Eggs were obtained from a culture maintained at the Insectary and Quarantine Facility, University of Tehran. The culture was reared at $25 \pm 1^{\circ} \mathrm{C}$ on wheat flour and yeast (5\%). About 20 mated female moths were kept in glass containers $(500 \mathrm{ml})$ to provide eggs and eggs were collected daily to ensure that living eggs used in the experiments were no more than $24 \mathrm{~h}$ old. Prior to use in experiments, wasps were reared for 15 generations on E. kuehniella.

\section{Flight chamber}

The flight chamber used in the experiments was similar to that previously described (Yong et al., 2007) with some modifications of the structure (Fig. 1). Air was driven through the main tunnel chamber $(200 \times 50 \times 50 \mathrm{~cm}, 1 \times \mathrm{w} \times \mathrm{h})$ by a fan located at the upwind end, and extracted outside by a fume hood at the downwind end. A smaller chamber $(50 \times 20 \times 20 \mathrm{~cm}$, $1 \times w \times h$ ), centered within the main chamber and open at both the upwind and downwind end, served as the experimental arena. The walls of the main chamber and experimental arena were made of transparent acrylic material. All flight responses were tested at $25^{\circ} \mathrm{C}, 50 \% \mathrm{RH}$, and a light intensity of 2000 lux.

In order to isolate parasitoid females for our experiments, small squares from egg cards (eggs were glued on cards $(1 \times 5 \mathrm{~cm})$ with $10 \%$ honey solution) were placed into emergence 
canisters and kept in incubators at $25 \pm 1^{\circ} \mathrm{C}, 16 \mathrm{~L}: 8 \mathrm{D}$ and $50 \% \pm 5 \% \mathrm{RH}$. Emergence canisters consisted of closed cardboard cylinders $(500 \mathrm{~mL}, 63 \times 161 \mathrm{~mm})$ with a glass vial (50 $\mathrm{mL}, 26 \times 93 \mathrm{~mm}$ ). Once approximately 20 parasitoids had emerged into a glass vial, they were removed and provided with undiluted honey as a food source. The vials were subsequently closed with a ventilated plastic cap to serve as a holding container until the females were $24 \mathrm{~h}$ old.

\section{Preliminary test: Test of an innate preference for the odor of peppermint or lemon}

To study the innate preference of the wasps towards one odor (peppermint and lemon odors were tested) against a filter paper without odor, 50 naïve wasps of each strain were exposed to either the odor of peppermint or the odor of lemon in the wind tunnel and their responses were recorded. To do this, single naïve female wasps were introduced into the flight chamber described above using a $5 \mathrm{~mL}$ shell vial. The tested odor was presented on strips of filter paper $(1 \times 2 \mathrm{~cm})$ on which $1 \mu \mathrm{L}$ of one or other solution (peppermint or lemon) had been placed on one filter paper, and no odor on the second filter paper. Each filter paper was attached to a glass pipette placed vertically on a stand and spaced $10 \mathrm{~cm}$ apart. Twentyfive of the 50 wasps underwent this procedure using the peppermint odor (at least $97 \%$ pure) and the other 25 underwent the procedure using the lemon odor (at least $97 \%$ pure). The responses of the wasps to the odors were observed in the flight tunnel during a flight time of 15 min. Any individual that landed or hovered on an odor site for more than 2 minutes was recorded as a responder wasp. Females that did not complete a flight or did not fly after 5 min were scored as displaying no response. Preliminary tests revealed that if females alighted for more than 2 minutes on an odor, they remained on the odor until the end of the 15 minute test 
period. If females failed to fly during the first 5 minutes, the female would choose neither odor during the experimental duration.

\section{Conditioning}

Sixty-five one-day old naïve females were exposed to host eggs for 15 minutes to gain oviposition experience and to avoid the variability in sequence and duration of behavioral events associated with learning from the first host encountered (Mills \& Kuhlmann, 2004). As some females died, were lost, or failed to oviposit during the procedure, sixty wasps in vials $(2 \times 10 \mathrm{~cm})$ with 100 host eggs (one-day old eggs glued onto cardboard) were transferred into conditioning tanks $(25 \times 25 \times 25 \mathrm{~cm})$. The conditioning odor was pumped into the tanks during conditioning at an air speed of $1 \mathrm{~m} / \mathrm{s}$. Thirty wasps underwent this conditioning procedure using peppermint odor, and the other thirty underwent it using lemon odor. This procedure was carried out using both uninfected and infected females, and lasted a duration of 2 hours.

\section{Experiments}

Experiment 1: test of odor preference after conditioning Fifteen minutes after conditioning, females of both strains were placed individually in the flight chamber as described above. The responses of 50 female wasps (randomly selected from amongst the survivors of the 60 originally conditioned), 25 of which had been conditioned on peppermint and 25 conditioned on lemon, were tested for both strains. Females that demonstrated a preference for the conditioned odor (i.e. any individual that landed or hovered on the conditioned odor site for more than 2 minutes), were scored as having learned to associate this odor (that was perceived as neutral in the preliminary test) with oviposition. The numbers 
of neutral responses displayed by the wasps were compared to identify the effects of Wolbachia on changes in the behavioral response in both strains and the ability of the strains to learn.

\section{Experiment 2: memory duration after one and multiple experiences Memory} (retention) was defined as being present when wasps displayed a post-conditioning significant preference for the conditioned odor (peppermint/lemon) in the case of wasps conditioned on peppermint or lemon respectively, compared to the unconditioned odor, at the time tested after the conditioning. To determine the duration of memory, the responses of conditioned wasps of both strains were observed $2,4,6,8,10,12,14,16,18,20,24$, and 30h after conditioning. Their responses for the odors of peppermint and lemon were recorded in the flight tunnel under the conditions previously described. For each time interval, 50 wasps of each strain (i.e. 25 conditioned for each odor) were observed in the wind tunnel as described above, amounting to a total of 1200 wasps tested.

The wasps were conditioned 1 to 5 times consecutively to show how the number of additional experiences affects memory duration of females. To do this, we divided the total conditioning time (120 min) into 1 to 5 periods, i.e. $120,60,40,30,24 \mathrm{~min}$ for one to five learning sessions, respectively. During each training session, when the wasps were in contact with the odor, they were offered 100 host eggs, as described above, and their responses were tested in the flight tunnel $15 \mathrm{~min}$ after the last conditioning. The time interval between successive training sessions was $6 \mathrm{~h}$ between the first and second session, and $4 \mathrm{~h}$ between each of the other training sessions, so that the wasps were no more than $24 \mathrm{~h}$ old after all 5 training sessions. During the intervals between the training sessions, the conditioned wasps were kept at $25 \pm 1^{\circ} \mathrm{C}, 50 \% \pm 5 \% \mathrm{RH}$ and $16: 8 \mathrm{~L}: \mathrm{D}$ and fed with a $10 \%$ honey solution. For each test, the responses of 50 wasps of each strain (25 conditioned with peppermint, and 
25 with lemon) were recorded. The wasps' responses were observed every 2 hours, so that a total of 11,400 wasps were tested (5700 per strain).

\section{Statistical analysis}

The innate responses of both strains were compared by Chi-Square tests using SAS software (SAS Institute, 2003). To compare the responses of the two strains before and after conditioning we used the Generalized Linear model implemented in the procedure GENMOD of SAS software (ver. 9.1), with the binomial family error and logit link. After this global test, the least square estimates of the proportions in each level were compared by the Chisquare approximation (an option offered by GENMOD).

The estimation of forgetting relies on a series of observations recorded at different times $\mathrm{t}_{1}$; $\mathrm{t}_{2} ; \ldots \mathrm{t}_{\mathrm{n}}$ after conditioning. At each time, a set of $n_{t}$ subjects was subjected to a choice test with three possible responses: $a ; b$; and $c$, which correspond respectively to a preference for the odor side, a preference for the opposite side (no odor), and to a null choice, i.e. no answer. The time courses of these three responses are illustrated. The forgetting of conditioning results in a switch from a high level to a lower level of positive responses, a simultaneous switch from a low level to a high level of null responses, and a switch from a very low to a moderate level of negative responses. A constraint links the three responses as $n_{a}+n_{b}+n_{c}=$ $n_{t}$ or $n_{c}=n_{t}-n_{a}-n_{b}$. The course of these three responses over time can be described by two logistic functions written here as probabilities,

$p_{a}, p_{b}, p_{c}$, constrained by $p_{a}+p_{b}+p_{c}=1$ :

$$
\begin{array}{r}
p_{a}=k_{a}-\frac{k_{a}-a_{a}}{1+e^{\left(-b_{a}(t-t 0)\right)}}+a_{a} \\
p_{c}=\frac{k_{c}-a_{c}}{1+e^{\left(-b_{c}(t-t 0)\right)}}+a_{c}
\end{array}
$$

$$
p_{b}=1-p_{a}-p_{c}
$$


$k_{a}$, respectively $k_{c}$, and $a_{a}$, respectively $a_{c}$ define the sill and baselines of the logistic models (1) and (2): the baselines are $a_{a}$ and $a_{c}$, and the seals are $k_{a}+a_{a}$ in model(1), $k_{c}+a_{c}$ in model (2). $k_{a}+a_{a}$ estimates the initial state in model (1), and $a_{c}$ the final state. It is the inverse in model (2), where $\mathrm{a}_{\mathrm{c}}$ is the initial state and $k_{c}+a_{c}$ the final state.

A supplementary restriction lies in the fact that, as t0 represents the mean time to oblivion, i.e. the inflection time point of the logistics functions; it has to be the same in all three equations. The data consist of a vector of three counts: $V_{t}=\left(n_{a t}, n_{b t}, n_{c t}\right)$ the respective number of subjects responding $\mathrm{a}$; $\mathrm{b}$ or $\mathrm{c}$ at time $\mathrm{t}$. An $\mathrm{R}$ script was written to do this. The experimental design was a balanced factorial design with two factors: firstly, the type of strain, which had two levels (uninfected and infected), and, secondly, the number of conditioning experiments, which had five levels. This design resulted in ten crossed levels. The model defined by equations 1 to 3 was fitted individually on each set of ten data. The maximization of the likelihood cannot be fully automatic, and requires an initial guess of the seven parameters ka; aa; ba; kc; ac; bc; t0. This was done by a visual evaluation of each graphic representation of the crossed levels. The maximization of the likelihood provides a starting point for each of the seven parameters to the algorithm. This was done by considering each graphic representation of the crossed levels (Bouvier \& Huet 1994). As an example, in figure 4 (Uninfected wasp (lemon)), we begin by ${ }^{t_{0}}$ which represents the common inflection point of the three curves, initially set to 21 . The initial level of response (seal) which represents $k_{a}+a_{a}$ was then set to 20 , and ${ }^{a_{a}}$, representing the final level of response, was set to 9 . As a result, ${ }^{k_{a}}$ was set initially to $20-9=11$. The exponential coefficients ( ${ }^{b}$ equation (1) and ${ }^{b}$ equation (2)), which are more difficult to evaluate graphically, where set to an arbitrarily low value such as 0.01 , which ensures a nice convergence of the algorithm. The 
function returns an error message if the algorithm does not reach the convergence, and in this case, other initial values were tried. Non-linear regression is also susceptible to a well known pitfall: the convergence toward a local maximum. In this case, the fitted curves poorly fit some parts of the data, and other initial values must be chosen to obtain the best fit. All these procedures where used when needed, and the correct fit was obtained in all cases. Only the final values for $t_{0}$ are given. In the example, the initial guess was 20 , and the final convergence was obtained at 21 . The algorithm provides the standard error for the final parameters, which enables us to assign them a confidence interval (Table 2). After maximization, we obtained seven estimates of each parameter, along with an estimate of their standard error through the hessian matrix, which is provided on demand by the optim function of R (R core team 2013). All correlations between pairs of coefficients were lower than 0.9; a threshold commonly accepted as critical for the correct inversion of the hessian matrix [Bouvier (1996), by Bouvier \& Huet, (1994)]. As our main focus was t0, we will give only the results for this parameter, which was accurately estimated with standard errors ranging from 0.3 to 1.8 hours. 


\section{Results}

Preliminary test: Test for an innate preference for peppermint or lemon odor

Naïve females of both the uninfected $\left(\chi^{2}=0.13, P=0.93, \mathrm{df}=2, N=50\right)$ and the infected $\left(\chi^{2}=0.69, P=0.70, \mathrm{df}=2, N=50\right)$ strains displayed no significant preference for the odor of lemon or this of peppermint against the filter paper with no odor or for an absence of a response $\left(\chi^{2}=0.95, P=0.62, \mathrm{df}=4, N=100\right)$ (Fig. 2).

\section{Experiment 1: test of odor preference after conditioning}

For uninfected wasps, the rate of an absence of response decreased significantly after conditioning for both odors, whereas it did not for the infected wasps (GENMOD of SAS, lemon odor: $\chi^{2}=6.36, P=0.0117, \mathrm{df}=1, N=25$; peppermint odor: $\chi^{2}=5.67, P=0.0173$, df $=1, \quad N=25$ for uninfected wasps and lemon odor: $\chi^{2}=0.37, P=0.5451, \mathrm{df}=1, N=25$; peppermint odor: $\chi^{2}=0.1, P=0.7578, \mathrm{df}=1, N=25$ for infected wasps)(Table 1, Fig. 3a). For both strains, the rate of positive responses for the odor in the presence of which they had been conditioned increased significantly after conditioning (Proc GENMOD of SAS: lemon odor: $\chi^{2}=10.59, P=0.0011$, df $=1, N=25$; peppermint odor: $\chi^{2}=9.08, P=0.0026, \mathrm{df}=1$, $\mathrm{N}=25$ for uninfected wasps and lemon odor: $\chi^{2}=6.18, P=0.0129, \mathrm{df}=1, \quad N=25$; peppermint odor: $\chi^{2}=7.55, P=0.006, d f=1, N=25$ for infected wasps (Table 1, Fig. $3 b$ ). Infection by Wolbachia then has no effect on this parameter. The rate of opposite responses were $1.0 \% \pm 0.5 \%$ and $4 \% \pm 1 \%$ for uninfected wasps conditioned with peppermint and lemon respectively, while this rate was $8 \% \pm 1 \%$ and $12 \% \pm 2 \%$ for infected wasps conditioned with peppermint and lemon. 
For a particular strain, the time to oblivion increases with the number of experiences undergone by the animals, and for a defined number of conditioning experiences, the uninfected strain retained the conditioning for longer than the infected strain (Table 2, Fig. 5). A three-factor variance analysis was done to verify these conclusions. Differences between the types were highly significant $\left(F_{1,393}=376.2, P<0.001\right)$, as were the number of experiences $\left(F_{4,393}=305.3, P<0.001\right)$, odor type $\left(F_{1,393}=1.004, P<0.001\right)$, and their interaction $\left(F_{1,390}=0.024, P=<0.001\right)$. The interaction clearly arises from two different levels (1 and 2) of the number of experiences, where the difference between uninfected and infected strains was much lower than at other levels (Fig. 5). Figure 5 also shows that in both strains, memory duration increased in response to the number of learning experiences undergone.

After one training session, the memory duration of the uninfected wasps was 23.88 and 21.47h, on lemon and peppermint respectively. For infected wasps on the same odors, these values were 18.94 and $16.27 \mathrm{~h}$ respectively. After five training sessions, the memory duration was 57.86 and $58.29 \mathrm{~h}$ for uninfected wasps on lemon and peppermint respectively, while it was 40.27 and $41.23 \mathrm{~h}$ for infected wasps on the same odors.

\section{Discussion}

Our results showed that the infected wasps presented a different behavior and particularly a reduced memory duration. After conditioning, the number of no responses decreased significantly for the uninfected wasps, whereas infected wasps showed the same number of no responses before and after conditioning: almost $30 \%$ of females of the infected strain 
never displayed orientation to conditioned odor. However, the memory duration of the infected wasps who were able to learn (i.e. who displayed an orientation towards the conditioned odor), was significantly shortened, regardless of the number of training sessions undergone. As our two strains had the same genetic background (Kishani Farahani et al., 2015), their difference in memory retention should be attributed first to the Wolbachia infection of the infected strain. This reduced memory duration could result from the manipulation of host behavior by Wolbachia, intended to increase Wolbachia transmission. Another possibility is that this reduced memory retention is more adaptive for infected wasps for their own fitness or may be due to some other unknown activity of host manipulation by Wolbachia.

The infected females, which were able to learn or to use their learning ability, always displayed shorter memory duration, irrespective of how many training sessions they had undergone. It has been predicted that information will only be used if it is useful for predicting the future (Stephens, 1989), and it has been suggested that factors such as the number of particular events, the reliability of the information and the rate of environmental change could all influence the cost-benefit balance of information use (Roitberg et al., 1993; Stephens, 1993; Dukas, 1998). The impact of the utility of the information on the learning ability was elegantly demonstrated by Theil et al. (2013) who studied two strains of Venturia canescens, one thelytokous and one arrhenotokous, but unlike the strains used in our study, their strains live in different habitats and the thelytokous form is not infected by Wolbachia (Foray et al., 2013). The thelytokous wasp V. canescens lives in habitats with relatively stable host-substrate associations and may encounter high levels of hosts. They showed a preference for a new odor after only a single experience. However, the response faded within $24 \mathrm{~h}$, even when the learning experiences had been spaced out, and the response did not 
develop into a long-term memory. The arrhenotokous wasp $V$. canescens lives in habitats where hosts are scarce and are likely to be found on a variety of substrates. Unlike the thelytokous wasps, arrhenotokous wasps learned a new odor after a single experience, and the memory lasted more than $24 \mathrm{~h}$. The authors hypothesized that in a habitat in which hosts are encountered relatively frequently, memory that simply covers the interval until the next host encounter might be sufficient, particularly if the cost of constructing this memory can be reduced by not using protein synthesis-dependent memory. This is the first example demonstrating a difference in learning ability between two strains of a parasitoid species with different sexuality, but in this case the difference in learning ability seems to be adaptive and linked to the fact that the two strains use different habitats.

In our case, it is impossible to separate the effects of infection from the effects of reproductive mode, but both our strains inhabit the same microhabitat, and it is unlikely that the decrease in memory retention could be adaptive for the infected strain, subjected to the same ecological constraints of that of the uninfected strain. If it is not adaptive for the infected wasps to have a decreased memory capacity, two hypotheses remain: firstly, the differences in memory retention could be attributable to host manipulation by Wolbachia to increase their transmission or secondly, such differences could be attributable to a negative by-product of the infection. Concerning the hypothesis of host manipulation, according to Gautestad and Mysterud's (2013) theoretical model of memory, a wider dispersal range (i.e. using a larger space) is to be expected for wasps with a shorter memory horizon (duration). This phenomenon could increase the likelihood for a transition to full dispersal, making returns to previously-visited environments unlikely. Simulation studies suggest that memory can eventually shape the spatial distribution of the population (Bernstein et al., 1988, 1991). If this applies to our case, the shorter memory duration may induce a greater dispersal rate of 
infected wasps. This behavior would be useful to the Wolbachia as it enables the parasite to contaminate new hosts. Indeed, Wolbachia can be transmitted via the superparasitism behavior of their hosts by horizontal transmission (i.e. when a female oviposits into a host that has already been parasitized, the contaminated larvae can transmit the Wolbachia to the other larvae present in the host, (Huigens et al., 2000, 2004)). A previous study (Kishani Farahani et al., 2015) has shown that infected females display higher superparasitism rates. As infected wasps produce only female offspring, it would lead to lower genetic diversity among this population in comparison to uninfected populations (Stelzer 2011; Simon et al. 2003). On the other hand, Huigens et al. (2004) showed that competition ability of Wolbachia infected wasps was lower than this of sexual wasps. Thus lower memory duration may help infected wasps to disperse in new environments and avoid competition with uninfected wasps by forgetting cues related to previously visited environments. This phenomenon may lead to a larger potential for a transition towards full dispersal, with a small chance of returning to previously visited environments. Simulation studies suggest that learning can eventually shape the spatial distribution of the population (Bernstein et al., 1988, 1991). Lower memory duration allows wasps to disperse in new environments and to mix with other populations, thus leading to greater genetic variations among populations.

We found that memory duration in individuals of both strains increased as a function of the number of experiences. In classical conditioning experiments, conditioning trials that are spaced out over time produce better conditioning than those that are clustered together in time (Terrace et al., 1975; Rescorla \& Durlach, 1987; Barnet et al., 1995; Beck et al. 2000). Interest in trial spacing has been renewed in recent years, because of claims that the perception of time is central to conditioning. A number of mechanisms can contribute to the trial spacing effects in classical conditioning (Barela, 1999). According to Gallistel and 
Gibbon (2000), the acquisition of conditioned responses depends on the animal deciding that the rate of reinforcement under the conditioned stimulus (CS) condition is higher than that in the background (Gibbon \& Balsam, 1981). By repeating learning events, the animals will be confronted by the stimuli several times, and this leads the animals to overestimate the extent of conditioned stimuli. A higher rate of encountering CS can reveal the importance of this stimulus for the animal, and thus it will be considered to be a high value stimulus in the animal's life. According to our results, both strains responded positively to repeat conditioning and increased their memory duration. However, in all additional experience tests, memory duration was shorter for the infected wasps than for the uninfected wasps. This may have been due to host manipulation by Wolbachia. Lower memory retention can be an adaptive strategy for time limited animals such as parasitoids. In other short-living species such as Anaphes victus (Hymenoptera: Mymaridae), for which longevity is around 2 days, it was shown that an associative learning ability allows the females to gain around 2 minutes at each oviposition and is thus adaptive (Van Baaren \& Boivin, 1998). It has been shown that $T$. brassicae survive 3-4 days when provided with food and oviposition (Lundgren \& Heimpel, 2003). As memory formation is costly (Burger et al., 2008; Gleiss et al., 2013), we can hypothesize that Wolbachia infection prevents the formation of longer-term memory to save energy as an adaptive strategy increasing Wolbachia transmission.

Several studies have shown that Wolbachia infection can change body organ function and structure, leading to changes in arthropod life style, in their use of hosts, and in their spread throughout the natural environment. Two recent reports have shown that Wolbachia infection of Drosophila melanogaster increases resistance to four types of RNA viruses, some of which are common in both field and laboratory cultures (Brun \& Plus, 1978; Ryder et al., 2004; Zambon et al., 2006). Similar protection from natural enemies has sometimes been 
observed in other arthropods (Gil-Turnes et al., 1989; Gil-Turnes \& Fenical, 1992; Haine et $a l ., 2005)$. This suggests that adaptation to specific conditions may depend on direct selection of symbionts expressing ecologically-important traits and simultaneously on indirect selection of the host. The effects of Wolbachia infection on memory duration can have a major impact on host ecology by widening the host's niche, thus allowing the host to exploit particular resources. Endosymbiotic Wolbachia bacteria are known to affect the fecundity and dispersal of infected strains (Stouthamer \& Luck, 1993; Silva, 1999). Some studies have shown that Wolbachia can infect the Central Nervous System of adult and juvenile hosts (Albertson et al., 2013; Strunov et al.. 2013). Wolbachia may affect parts of the nervous system, such as the mushroom bodies which make hosts forage in more patches, thus spreading the Wolbachia infection and increasing the probability that genes will be dispersed in the natural environment. However, further research should be done to investigate the effects of Wolbachia infection on the central nervous system or on other organs involved in lifetime information acquisition. Moreover, these behavioral differences could either be due to negative side effects on mobility behavior, or on perception capacity for example, or due to a negative effect on learning ability, although our experiments did not allow us to differentiate. As nothing is known about the possible other heritable symbionts associated with these lines (e.g., Rickettsia, Spiroplasma, Cardinium, etc), we cannot be completely sure that they have no role. However, more research is required to investigate the molecular and neural bases of learning and memory formation, for example, tracking the neurotransmission processes in uninfected and infected $T$. brassicae brain structures.

\section{Acknowledgments}

We would like to thank Akbar Golshani, Pouria Abrun and Valérie Briand, for the technical support provided and also appreciate the assistance of Dr. Lucy Alford and Monica Gosh for 
help with the language and writing. This study was financially supported by University of Tehran, but the sponsor had no involvement in the study design, the collection, analysis, or interpretation of data, the writing of the report or in the decision to submit the paper for publication.

\section{References}

Adcock, R.A., Thangavel, A., Whitfield-Gabrieli, S., Knuston, B. and Gabrieli, J.D.E. (2006) Reward-motivated learning: mesolimbic activation precedes memory formation. Neuron, 50, $507-517$.

Albertson, R., Tan, V., Leads, R.R., Reyes, M., Sullivan, W. and Casper-Lindley, C. (2013) Mapping Wolbachia distributions in the adult Drosophila brain. Cellular Microbiology, 15, $1527-1544$.

Ardiel, E.L. and Rankin, C.H. (2010) An elegant mind: learning and memory in Caenorahbditis elegans. Learning and Memory, 17, 191-201.

Barela, P.B. (1999) Theoretical mechanisms underlying the trial spacing effect in Pavlovian conditioning. Journal of Experimental Psychology: Animal Behavior Process, 25, 177-193. Barnet, R.C., Grahame, N.J. and Miller, R.R. (1995) Trial spacing effects in Pavlovian conditioning: A role for local context. Animal Learning \& Behavior, 23, 340-348.

Beck, C.D., Schroeder, B. and Davis, R.L. (2000) Learning performance of normal and mutant Drosophila after repeated conditioning trials with discrete stimuli. Journal of Neuroscience, 20, 2944-2953.

Bernstein, C., Kacelnik, A. and Krebs, J.R. (1988) Individual decisions and the distribution of predators in a patchy environment. Journal of Animal Ecology, 57, 1007-1026. 
Bernstein, C., Kacelnik, A. and Krebs, J.R. (1991) Individual decisions and the distribution of predators in a patchy environment II the influence of travel costs and structure of the environment. Journal of Animal Ecology, 60, 205-225.

Bouvier, A. and Huet, S. (1994) "Nls2 - Nonlinear-Regression by S-Plus - Functions". Computational Statistics \& Data Analysis, 18, 187-190.

Braig, H.R., Zhou, W., Dobson, S. and O'Neill, S.L. (1998) Cloning and characterization of a gene encoding the major surface protein of the bacterial endosymbiont Wolbachia. Journal of Bacteriology, 180, 2373-2378.

Braithwaite, V.A., Salkeld, D.J., McAdam, H.M., Hockings, C.G., Ludlow, A.M. and Read, A.F. (1998) Spatial and discrimination learning in rodents infected with the nematode Strongyloides ratti. Parasitology, 117, 145-154.

Beck, C.D.O., Schroeder, B. and Davis, R.L. (2000) Learning performance of normal and mutant Drosophila after repeated conditioning trials with discrete Stimuli. The Journal of Neuroscience, 20(8), 2944-2953.

Bruck, J.N. (2013) Decades long social memory in bottlenose dolphins. Proceedings of Royal Society of Biological Science, 280, 2011726.

Brun, G. and Plus, N. (1978) The viruses of Drosophila. The Genetics and Biology of Drosophila (eds. M. Ashburner \& T.R.F. Wright), pp. 625-702. New York: Academic Press. Burger, J.M.S., Kolss, M., Pont, J. and Kawecki. T.J. (2008) Learning ability and longevity: a symmetrical evolutionary trade-off in drosophila. Evolution, 62-6, 1294-1304.

Carew, T.J., Pinsker, H.M. and Kandel, E.R. (1972) Long-term habituation of a defensive withdrawal reflex in Aplysia. Science, 175, 451-454.

Cordaux, R., Pichon, S., Ben Afia hatira, H., Doublet, V., Greve, P., Marcade, I., BraquartVarnier, C., Souty-Grosset, C., Charfi-Cheikhrouha, F. and Bouchon, D. (2012) Widespread Wolbachia infection in trerrestrial isopods and other crustaceans. Zookeys, 176, 123-131. 
Cox, D.M. and Holland, C.V. (2001) Relationship between three intensity levels of Toxocara canis larvae in the brain and effects on exploration, anxiety, learning and memory in the murine host. Journal of Helminthology, 75, 33-41.

De Bartolo, P., Cutuli, D., Ricceri, L., Gelfo, F., Foti, F., Laricchiuta, D., Scattoni, M.L., Calamandrei, G. and Petrosini, L. (2010) Does age matter? Behavioral and neuro-anatomical effects of neonatal and adult basal forebrain cholinergic lesions. Journal of Alzheimers Disease, 20, 207-227.

Dedeine, F., Vavre, F., Fleury, F., Loppin, B., Hochberg, M.E. and Boule'treau, M. (2001) Removing symbiotic Wolbachia bacteria specifically inhibits oogenesis in a parasitic wasp. Proceedings of the National Academy of Sciences of the United States of America, 98, 62476252.

Dukas, R. (1998) Evolutionary ecology of learning. Cognitive Ecology: The Evolutionary Ecology of Information Processing and Decision Making (ed. R. Dukas), pp. 129-174. Chicago, IL: University of Chicago Press.

Dukas, R. (2008a) Evolutionary biology of insect learning. Annual Review of Entomology, $53,145-160$.

Dukas, R. (2008b) Learning decreases heterospecific courtship and mating in fruit flies. Biology Letters, 4, 645-647.

Dukas, R. and Bernays, E.A. (2000) Learning improves growth rate in grasshoppers. Proceedings of the National Academy of Sciences of the United States of America, 97, 26372640.

Dukas, R. (2013) Effects of learning on evolution: robustness, innovation and speciation. Animal Behavior, 85, 1023-1030. 
Fangan, W.F., Lewis, M.A., Auger-Methe, M., Avgar, T., Benhamou, S., Breed, G., LaDage, L., Schlagel, U.E., Tang, W., Papastamatiou, T.P., Forester, J. and Mueller, T. (2013) Spatial memory and animal movement. Ecology Letters, 16(10), 1316-1329.

Fanselow, M.S. and Tighe, T.J. (1988) Contextual conditioning with massed versus distributed unconditional stimuli in the absence of explicit conditional stimuli. Journal of Experimental Psychology, 14, 187-199.

Farrokhi, S., Ashouri, A., Shirazi, J., Allahyari, H. and Huigens, M.E. (2010) A comparative study on the functional response of Wolbachia-infected and uninfected forms of the parasitoid wasp Trichogramma brassicae. Journal of Insect Science, 10, 167.

Fialho, R.F. and Stevens, L. (2000) Male killing Wolbachia in a flour beetle. Proceedings of the Royal Society of London B, 267, 1469-1473.

Foray, V., Henri, H., Martinez, S., Gibert, P. and Desouhant, D. (2013) Occurrence of arrhenotoky and thelytoky in a parasitic wasp Venturia canescens (Hymenoptera: Ichneumonidae): Effect of endosymbionts or existence of two distinct reproductive modes?. European Journal of Entomology, 110, 103-107.

Gallagher, M. and Rapp, P.R. (1997) The use of animal models to study the effects of aging on cognition. Annual Review of Psychology, 48, 339-370.

Gallistel, C.R. and Gibbon, J. (2000) Time, rate, and conditioning. Psychological Review, $107,289-344$.

Gautestad, A.O. and Mysterud, A. (2013) The Lévy flight foraging hypothesis: forgetting about memory may lead to false verification of Brownian motion. Movement Ecology, 1, 9.

Gegear, R.J., Otterstatter, M.C. and Thomson, J.D. (2006) Bumble-bee foragers infected by a gut parasite have an impaired ability to utilize floral information. Proceedings of the Royal Society of London B, 273, 1073-1078. 
Gibbon, J. and Balsam, P.D. (1981) Spreading associations in time. Autoshaping and Conditioning Theory (eds. C.M. Locurto, H.S. Terrace \& J. Gibbon), pp. 219-253. New York: Academic Press.

Gil-Turnes, M.S., Hay, M.E. and Fenical, W. (1989) Symbiotic marine bacteria chemically defend crustacean embryos from a pathogenic fungus. Science, 246, 116-118.

Gil-Turnes, M.S. and Fenical, W. (1992) Embryos of Homarus americanus are protected by epibiotic bacteria. The Biological Bulletin, 182, 105-108.

Giurfa, M. (2007) Behavioral and neural analysis of associative learning in the honeybee: a taste from the magic well. Journal of Comparative Physiology A, 193, 801-824.

Giurfa, M. and Sandoz, J.C. (2012) Invertebrate learning and memory: fifty years of olfactory conditioning of the proboscis extension response in honeybees. Learning \& Memory, 19, 5466.

Giunti, G., Canale, A., Messing, R.H., Donati, E., Stefanini, C., Michaud, V. and Benelli, G. (2015) Parasitoid learning: Current knowledge and implications for biological control. Biological Control, 90, 208-219.

Gleiss, A.C., Wilson, R.P. and Shepard, E.L.C. (2011) Making overall body dynamic acceleration work: on the theory of acceleration as a proxy for energy expenditure. Methods in Ecology and Evolution, 2, 23-33.

Grenier, S. and De Clercq, P. (2003) Comparison of artificially vs. naturally reared natural enemies and their potential for use in biological control. Quality Control and Production of Biological Control Agents Theory and Testing Procedures (ed. J.C. van Lenteren), pp. 115131. CAB Publishing, Wallingford.

Goodacre, S.L., Martin, O.Y., Thomas, C.F.G. and Hewitt, G.M. (2006) Wolbachia and other endosymbiont infections in spiders. Molecular Ecology, 15, 517-527. 
Haine, E.R., Boucansaud, K. and Rigaud, T. (2005) Conflict between parasites with different transmission strategies infecting an amphipod host. Proceedings of the Royal Society of London B, 272, 2505-2510.

Hermitte. G., Pedreira, M.E., Tomsic, D. and Maldonado, H. (1999) Context shifts and protein synthesis inhibition disrupt long-term habituation after spaced, but not massed, training in the crab Chasmagnathus. Learning \& Memory, 71, 34-49.

Hoedjes, K.M., Kruidhof, H.M., Huigens, M.E., Dicke, M., Vet, L.E.M. and Smid, H.M. (2010) Natural variation in learning rate and memory dynamics in parasitoid wasps: opportunities for converging ecology and neuroscience. Proceedings of the Royal Society of London B, doi: 101098/rspb20102199.

Hoffmann, M.P., Walker, D.L. and Shelton, A.M. (1995) Biology of Trichogramma ostriniae (Hym: Trichogrammatidae) reared on Ostrinia nubilalis (Lep: Pyralidae) and survey for additional hosts. Entomophaga, 40, 387-402.

Hohmann, C.L., Luck, R.F. and Stouthamer, R. (2001) Effect of Wolbachia on the survival and reproduction of Trichogramma kaykai Pinto and Stouthamer (Hymenoptera: Trichogrammatidae). Neotropical Entomology, 30(4), 607-612.

Huigens, M.E., Hohmann, C.L., Luck, R.F., Gort, G. and Stouthamer, R. (2004) Reduced competitive ability due to Wolbachia infection in the parasitoid wasp Trichogramma kaykai. Entomologia Experimentalis et Applicata, 110, 115-123.

Huigens, M.E., Luck, R.F., Klaassen, R.H.G., Maas, M.F.P.M., Timmermans, M.J.T.N. and Stouthamer, R. (2000) Infectious parthenogenesis. Nature, 405, 178-179.

Huigens, M.E. and Stouthamer, R. (2003) Parthenogenesis associated with Wolbachia. Insect Symbiosis (eds. K. Bourtzis \& T.A. Miller), pp. 247-266. CRC Press: Boca Raton, FL.

Iqbal, J. and Muller, U. (2007) Virus infection causes specific learning deficits in honeybee foragers. Proceedings of the Royal Society of London B, 274, 1517-1521. 
Kavaliers, M. and Colwell, D.D. (1995) Reduced spatial learning in mice infected with the nematode, Heligmosomoides polygyrus. Parasitology, 110, 1004-1017.

Kavaliers, M., Colwell, D.D. and Galea, L.A.M. (1995) Parasitic infection impairs spatial learning in mice. Animal Behavior, 50, 223-229.

Kishani Farahani, H., Ashouri, A., Goldansaz, S.H., Ainouche, A. and van Baaren, J. (2015) Does Wolbachia infestation affect decision making in a parasitic wasp?. Entomologia Experimentalis et Applicata, 155(2), 102-116.

Kralj, J., Brockmann, A., Fuchs, S. and Tautz, J. (2007) The parasitic mite Varroa destructor affects non-associative learning in honey bee foragers, Apis mellifera L. Journal of Comparative Physiology A, 193, 363-370.

Kralj, J. and Fuchs, S. (2006) Parasitic Varroa destructor mites influence flight duration and homing ability of infested Apis mellifera foragers. Apidologie, 37, 577-587.

Kremer, N., Charif, D., Henri, H., Gavory, F., Wincker, P., Mavingui, P. and Vavre, F. (2012) Influence of Wolbachia on host gene expression in an obligatory symbiosis. BMC Microbiology, 12, S7 10.1186/1471-2180-12-S1-S7.

Kogan, J.H., Frankland, P.W., Blendy, J.A., Coblentz. J., Marowitz, Z. and Silva, A.J. (1997) Spaced training induces normal long-term memory in CREB mutant mice. Current Biology, $7,1-11$

Kruidhof, H.M., Pashalidou, F.G., Fatouros, N.E., Figueroa, I.A., Vet, L.E.M., Smid, M.S. and Huigens, M.E. (2012) Reward value determines memory consolidation in parasitic wasps. PLoS ONE, 7(8), e39615 doi:101371/journalpone0039615.

Lundgren, J.G. and Heimpel, G.E. (2003) Quality assessment of three species of commercially produced Trichogramma and the first report of thelytoky in commercially produced Trichogramma. Biological Control, 26, 68-73. 
Mansfield, S. and Mills, N.J. (2002) Host egg characteristics, physiological host range, and parasitism following inundative releases of Trichogramma platneri (Hymenoptera: Trichogrammatidae) in walnut orchards. Environmental Entomology, 31, 723-731.

Menzel, R. and Müller, U. (1996) Learning and memory in honeybees: From behavior to neural substrates. Annual Review of Neuroscience, 19, 379-404.

Menzel, R. (1999) Memory dynamics in the honeybee. Journal of Comparative Physiology A, $185,323-340$.

Mery, F. (2013) Natural variation in learning and memory. Current Opinion in Neurobiology, $23,52-56$.

Mery, F. and Kawecki, T.J. (2005) A cost of long-term memory in Drosophila. Science, 308, 1148.

Mills, N.J. and Kuhlmann, U. (2004) Oviposition behavior of Trichogramma platneri Nagarkatti and Trichogramma pretiosum Riley (Hymenoptera: Trichogrammatidae) in patches of single and clustered host eggs. Biological Control, 30, 42-51.

Miura, K. and Tagami, Y. (2004) Comparison of life history characters of sexual and Wolbachia-associated asexual Trichogramma kaykai (Hymenoptera: Trichogrammatidae). Annals of the Entomological Society of America, 97(4), 765-769.

Muzzio, I.A., Ramirez, R.R., Talk, A.C. and Matzel, L.D. (1999) Interactive contributions of intracellular calcium and protein phosphatases to massed-trials learning deficits in Hermissenda. Behavioral Neuroscience, 113, 103-117.

Nishio, H., Kasuga, S., Ushijima, M., Harada, Y. (2001) Prenatal stress and postnatal development of neonatal rats-sex-dependent effects on emotional behavior and learning ability of neonatal rats. International Journal of Developmental Neuroscience, 19, 37-45.

Page, R.E.J. and Peng, C.Y. (2001) Aging and development in social insects with emphasis on the honey bee, Apis mellifera L. Experimental Gerontology, 36(46), 695-711. 
Panteleev, D.Y., Goryacheva, I.I., Andrianov, B.V., Reznik, N.L., Lazebny, O.E. and Kulikov, A.M. (2007) The endosymbiotic bacterium Wolbachia enhances the nonspecific resistance to insect pathogens and alters behavior of Drosophila melanogaster. Russian Journal of Genetics, 43(9), 1066-1069.

Pearce, J.M. (2008) Animal Learning and Cognition: An Introduction. 3rd edn. Psychology Press.

Petursdottir, A.L., Farr, S.A., Morley, J.E., Banks, W.A., Skuladottir, G.V. (2008) Effect of dietary n-3 polyunsaturated fatty acids on brain lipid fatty acid composition, learning ability, and memory of senescence-accelerated mouse. The Journals of Gerontology Series A: Biological Sciences and Medical Sciences, 63(11), 1153-1160.

Pinto, J.D. (1998) Systematics of the North American species of Trichogramma Westwood (Hymenoptera: Trichogrammatidae). Memoirs of the Entomological Society of Washington, $22,1-287$.

Poorjavad, N., Goldansaz, S.H., Machtelinckx, T., Tirry, L., Stouthamer, R. and van Leeuwen, T. (2012) Iranian Trichogramma: ITS2 DNA characterization and natural Wolbachia infection. BioControl, 57, 361-374.

Pravosudov, V.V. and Smulders, T. (2010) Integrating ecology, psychology and neurobiology within a food-hoarding paradigm. Philosophical Transactions of the Royal Society B, 365, 859-867.

Portavella, M., Torres, B. and Salas, C. (2004) Avoidance response in goldfish: emotional and temporal involvement of medial and lateral Telencephalic Pallium. Journal of Neuroscience, 24, 2335-2342.

Raine, N.E. and Chittka, L. (2008) The correlation of learning speed and natural foraging success in bumble-bees. Proceedings of the Royal Society of London, 275, 803-808. 
Rankin, C.H., Chiba, C. and Beck, C. (1990) Caenorhabditis elegans: A new model system for the study of learning and memory. Behavioral Brain Research, 37, 89-92.

Rescorla, R.A. and Durlach, P.J. (1987) The role of context in intertribal interval effects in auto shaping. Quarterly Journal of Experimental Psychology, 39, 35-40.

Roitberg, B.D., Reid, M.L. and Li, C. (1993) Choosing hosts and mates, the value of learning. Insect Learning: Ecological and Evolutionary Perspectives (eds. D.R. Papaj \& A.C. Lewis), pp. 174-194. Chapman and Hall, New York, NY.

Ryder, E., Blows, F., Ashburner, M., Bautista-Llacer, R., Coulson, D., Drummond, J., Webster, J., Gubb, D., Gunton, N., Johnson, G., O'Kane, C.J., Huen, D., Sharma, P., Asztalos, Z., Baisch, H., Schulze, J., Kube, M., Kittlaus, K., Reuter, G., Maroy, P., Szidonya, J., Rasmuson-Lestander, A., Ekström, K., Dickson, B., Hugentobler, C., Stocker, H., Hafen, E., Lepesant, J.A., Pflugfelder, G., Heisenberg, M., Mechler, B., Serras, F., Corominas, M., Schneuwly, S., Preat, T., Roote, J. and Russell, S. (2004) The DrosDel collection: a set of P-element insertions for generating custom chromosomal aberrations in Drosophila melanogaster. Genetics, 167, 797- 813.

SAS Institute (2003) SAS User's Guide: Statistics, version 91 SAS Institute, Cary, NC.

Schaie, K.W., Willis, S.L. and Caskie, G.I.L. (2004) The Seattle longitudinal study: Relationship between personality and cognition. Neuropsychology, Development, and Cognition. Section B, Aging, Neuropsychology and Cognition, 11(23), 304-324.

Shors, T.J. (2004) Learning during stressful times. Learn Memory, 11, 137-144.

Silva, I.M.M.S., van Meer, M.M.M., Roskam, M.M., Hoogenboom, A., Gort, G. and Stouthamer, R. (2000) Biological control potential of Wolbachia infected (unisexual) versus uninfected (sexual) wasps: Laboratory and greenhouse evaluation of Trichogramma cordubensis and T. deion strains. BioControl, 10, 223-238. 
Spieler, D.H. and Balota, D.A. (1996) Characteristics of associative learning in younger and older adults: Evidence from an episodic priming paradigm. Psychology and Aging, 11, 607620.

Stephens, D.W. (1993) Learning and behavioral ecology: incomplete information and environmental predictability. Insect Learning: Ecological and Evolutionary Perspectives (eds. D.R. Papaj \& A.C. Lewis), pp. 195-218. Chapman and Hall, New York, NY.

Stephens, D.W. (1989) Variance and the value of information. American Naturalist, 134, $128-140$.

Stouthamer, R. and Luck, R.F. (1993) Influence of microbe-associated parthenogenesis on the fecundity of Trichogramma deion and T. pretiosum. Entomologia Experimentalis et Applicata, 67, 183-192.

Strunov, A., Kiseleva, E. and Gottlieb, Y. (2013) Spatial and temporal distribution of pathogenic Wolbachia strain wMelPop in Drosophila melanogaster central nervous system under different temperature conditions. Journal of Invertebrate Pathology, 114, 22-30.

Suzuki, H., Park, S.J., Tamura, M. and Ando, S. (1998) Effect of the long-term feeding of dietary lipids on the learning ability, fatty acid composition of brain stem phospholipids and synaptic membrane fluidity in adult mice: a comparison of sardine oil diet with palm oil diet. Mechanisms of Ageing and Development, 101(12), 119-128.

Taylor, M.J. and Hoerauf, A. (1999) Wolbachia bacteria of filarial nematodes. Parasitology Today, 15, 437-442.

Terrace, H.S., Gibbon, J., Farrell, L. and Baldock, M.D. (1975) Temporal factors influencing the acquisition and maintenance of an auto shaped key peck. Animal Learning \& Behavior, 3, $53-62$. 
Theil, A., Schalke, S. and Kosior, D. (2013) Omnia tempus habent: habitat-specific differences in olfactory learning and decision making in parasitic wasps. Animal Cognition, $16,223-232$.

Timmermans, M.J.T.N. and Ellers, J. (2009) Wolbachia endosymbiont is essential for egg hatching in a parthenogenetic arthropod. Evolutionary Ecology, 23, 931-942.

Toppino, T.C. and Bloom, L.C. (2002) The spacing effect, free recall, and two-process theory: A closer look. The Journal of Experimental Psychology: Learning, Memory, and Cognition, 28(3), 437-444.

Tully, T., Preat, T., Boynton, S.C. and Del Vecchio, M. (1994) Genetic dissection of consolidated memory in Drosophila. Cell, 79, 35-47.

van Baaren, J., Boivin, G. and Outreman, Y. (2006) Deleterious effects of low temperature exposure on learning capacities in a parasitoid. International Journal of Comparative Psychology, 19, 368-385.

van Baaren, J. and Boivin, G. (1998) Genotypic and kin discrimination in a solitary Hymenopterous parasitoid: Implications on speciation. Evolutionary Ecology, 12, 523-534.

van Baaren, J., Outreman, Y., Boivin, G. (2005) Effect of low temperature exposure on oviposition behaviour and patch exploitation strategy in parasitic wasps. Animal Behaviour, 70, 153-163.

Weeks, A.R., Turelli, M., Harcombe, W.R., Reynolds, K.T. and Hoffmann, A.A. (2007) From parasite to mutualist: rapid evolution of Wolbachia in natural populations of Drosophila. PLoS Biology, 5, 997-1005.

Weiler, J.A., Bellebaum, C. and Daum, I. (2008) Aging affects acquisition and reversal of reward-based associative learning. Learning \& Memory, 15, 190-197 
Werren, J.H., Baldo, L. and Clark, M.E. (2008) Wolbachia: master manipulators of invertebrate biology. Nature Reviews Microbiology, 6, 741-751.

Wu, G.Y., Deisseroth, K. and Tsien, R.W. (2001) Spaced stimuli stabilize MAPK pathway activation and its effects on dendritic morphology. Nature Neuroscience, 4, 151-158.

Yong, T.H., Pitcher, S., Gardner, J. and Hoffmann, M.P. (2007) Odor specificity testing in the assessment of efficacy and non-target risk for Trichogramma ostriniae (Hymenoptera: Trichogrammatidae). Biocontrol Science and Technology, 17, 135-153.

Zambon, R.A., Vakharia, V.N. and Wu, L.P. (2006) RNAi is an antiviral immune response against a dsRNA virus in Drosophila melanogaster. Cell Microbiology, 8, 880-889.

Zchori-Fein, E., Gottlieb, Y., Kelly, S.E., Brown, J.K., Wilson, J.M., Karr, T.L. and Hunter, M.S. (2001) A newly discovered bacterium associated with parthenogenesis and a change in host selection behavior in parasitoid wasps. Proceedings of the National Academy of Sciences of the United States of America, 98, 12555-12560.

Accepted March 13, 2016 


\section{Figure legends}

Figure 1. Diagram of the wind tunnel. Air was driven through the main tunnel chamber at a speed of $2.5 \mathrm{~m} / \mathrm{s}$, peppermint and lemon odor (at least $97 \%$ pure). Arrows show the dimension of each part of wind tunnel. To avoid positional effects, after each 5 experiments the positions of the peppermint and lemon were displaced.

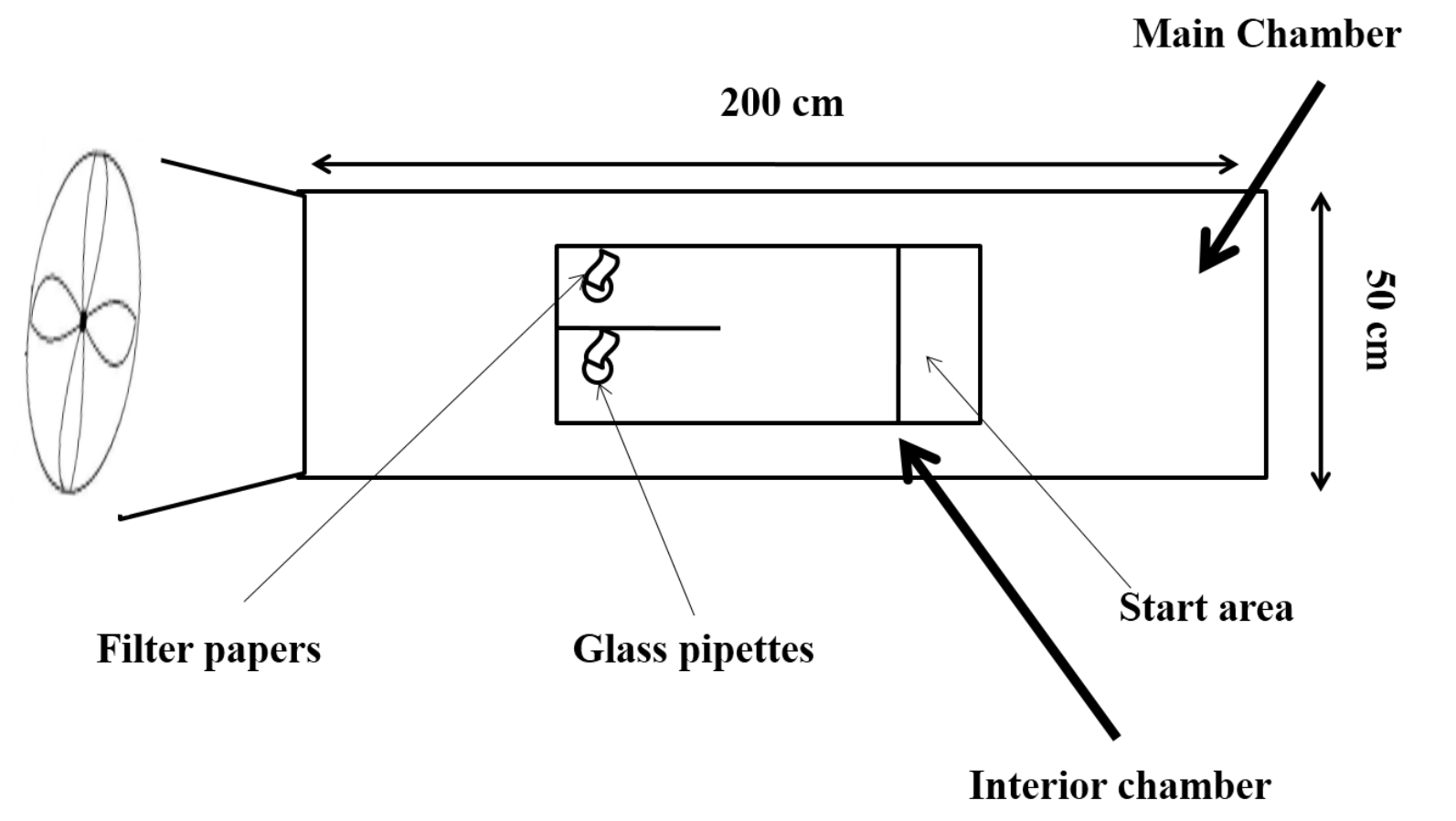


Figure 2. Percentage of recorded responses by naïve uninfected and infected wasps toward peppermint (A) or lemon (B) odor. The error-bars represent the confidence interval on percentage.

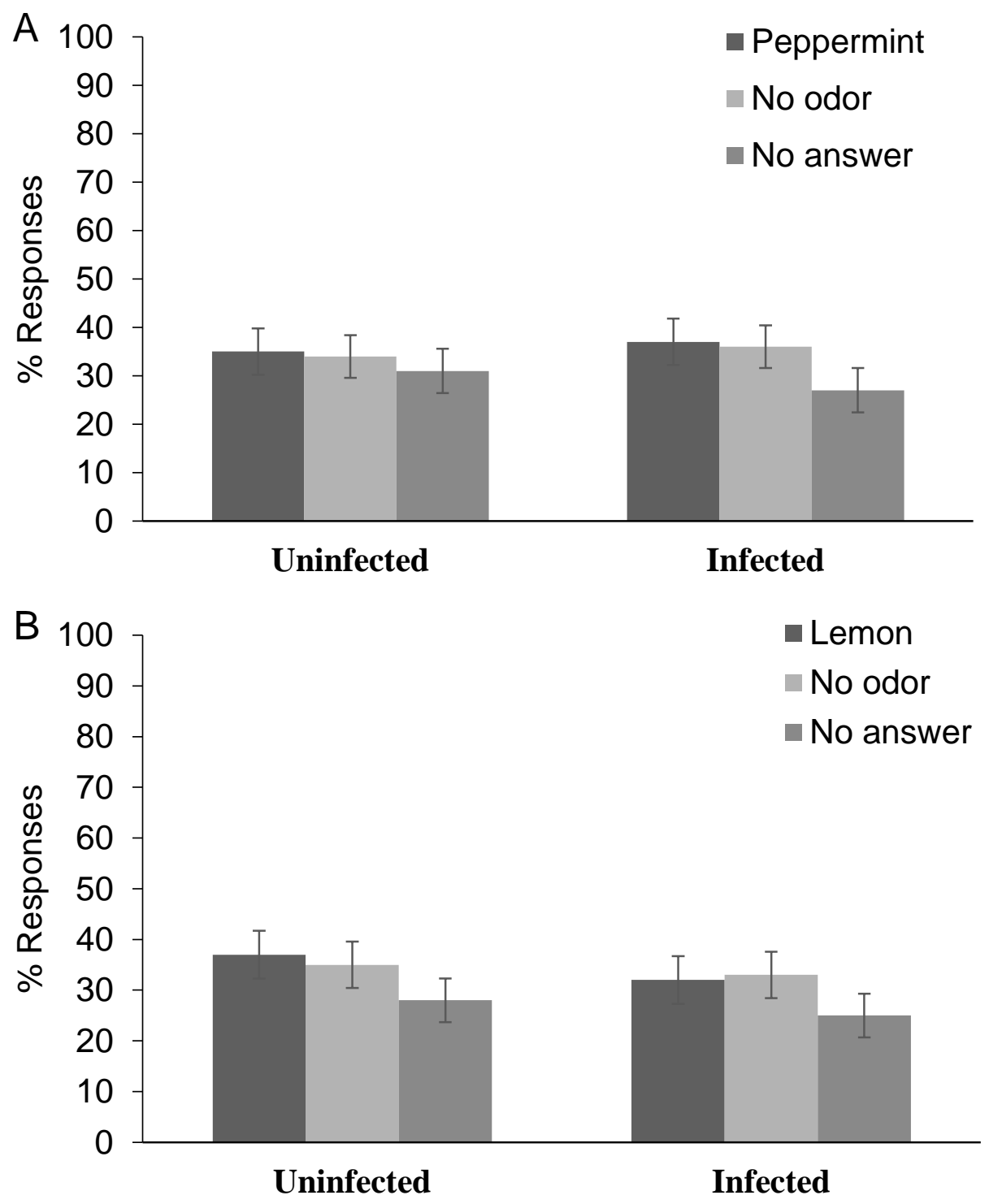


Figure 3. Percentage of recorded responses by wasps: (A) no response (B) positive response by uninfected and infected wasps after and before conditioning by peppermint and lemon odor, respectively. The responses of 25 wasps (uninfected, females only, and infected) to peppermint/lemon odor was compared. Different letters indicate statistically significant differences.
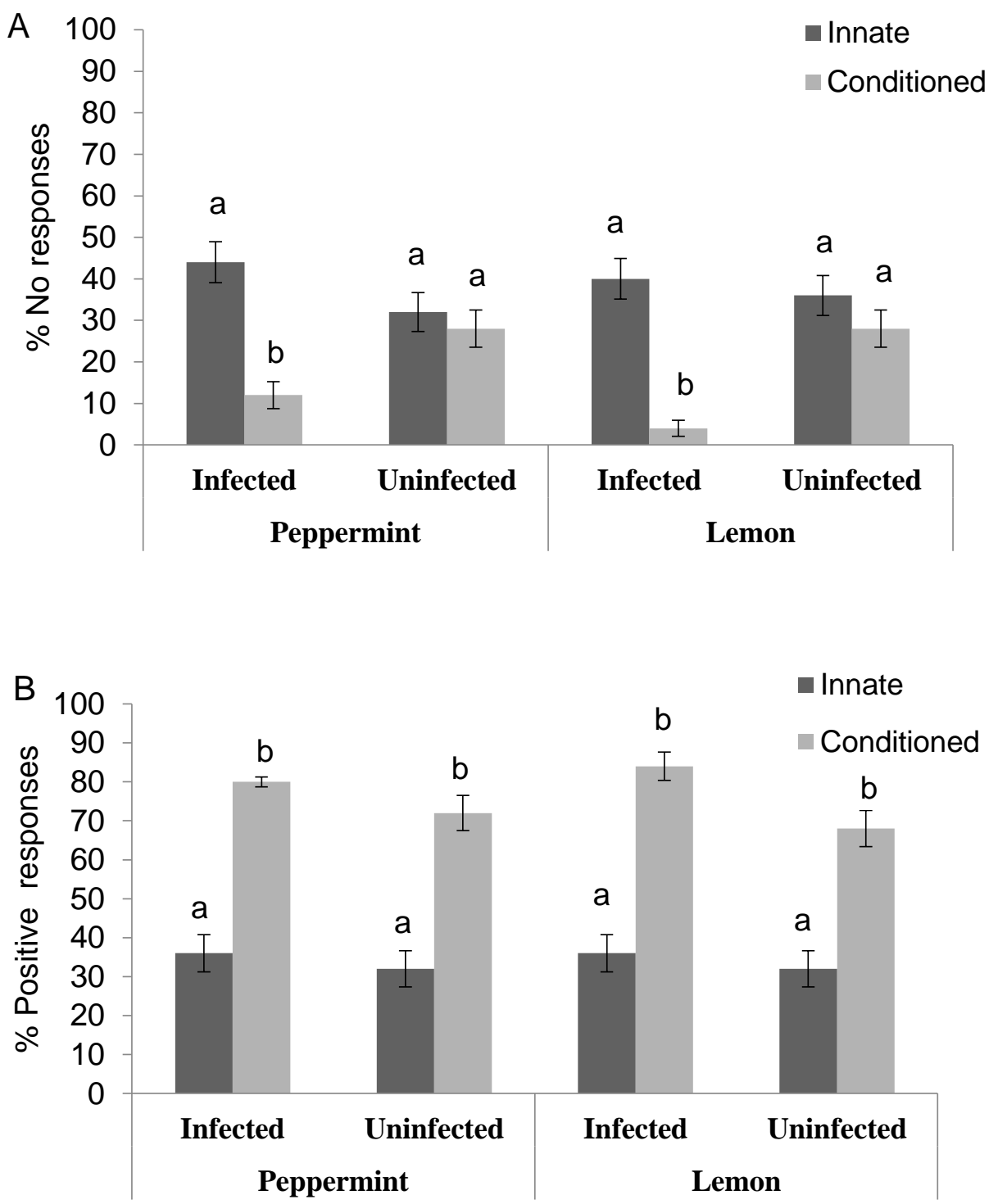
Figure 4. Time course of the three possible responses to odor of a set of a conditioned parasitoid after one previous experience. The dotted line indicates positive responses, the gray line negative responses, and the dot-dashed line the neutral responses over time.
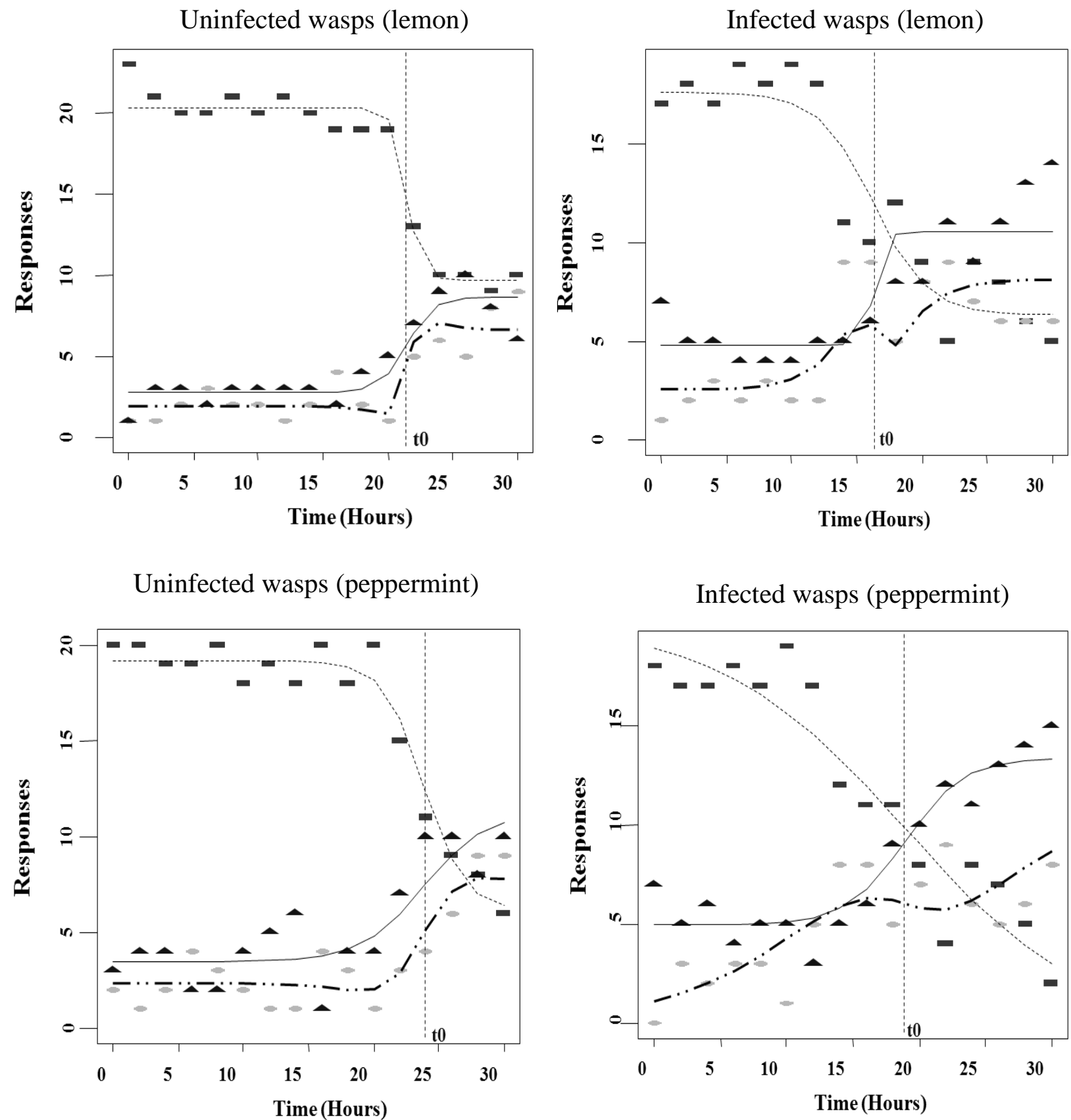
Figure 5. Differences in the forgetting mid-time depending on the number of conditioning experiences (abscissa) and the type of strain.

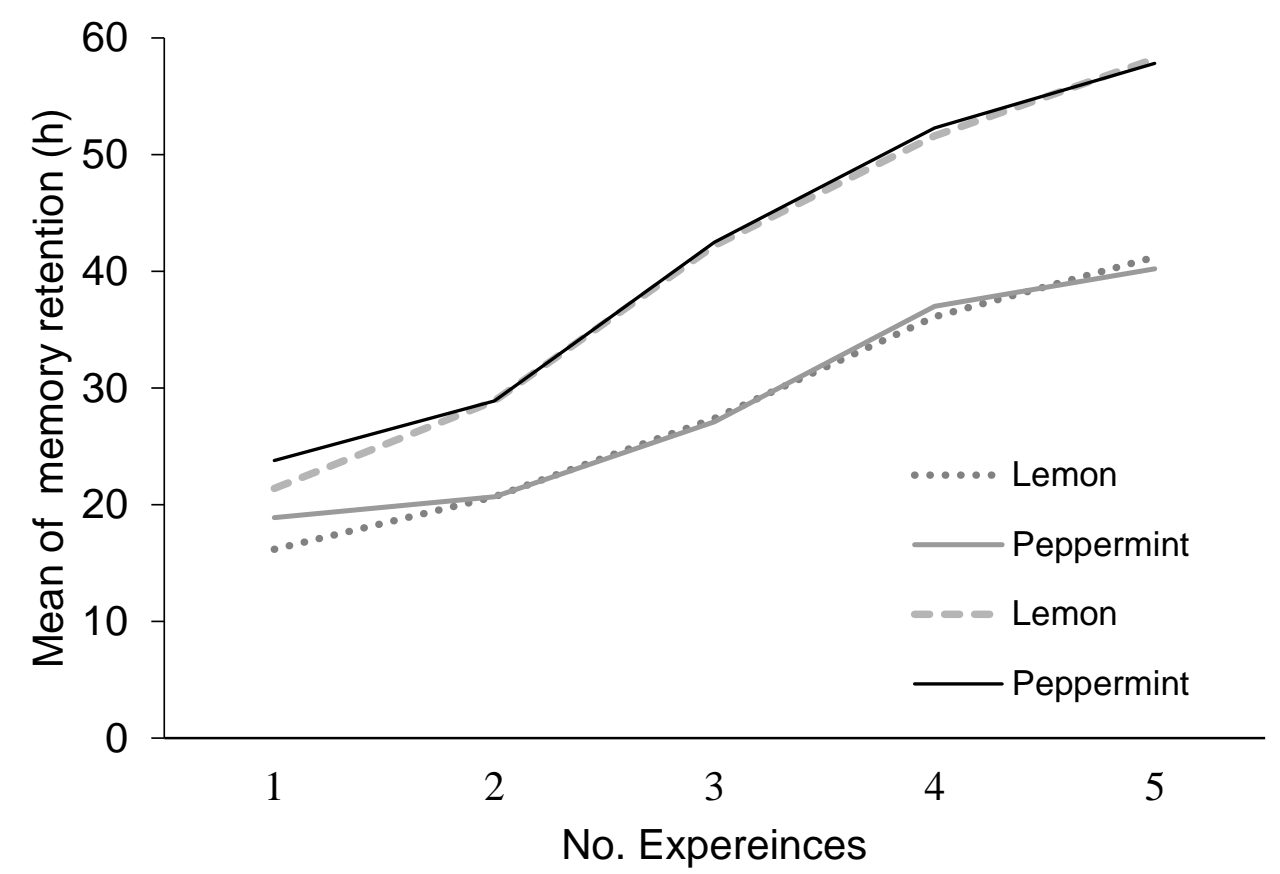


Table 1 Effects of the strain, conditioning, and interaction of these two factors on the wasps' responses. Significantly different results are shown in bold.

\begin{tabular}{|c|c|c|c|c|c|c|c|}
\hline & & \multicolumn{2}{|c|}{ Strain } & \multicolumn{2}{|c|}{ Conditioning } & \multicolumn{2}{|c|}{$\begin{array}{l}\text { Interaction between } \\
\text { strain and } \\
\text { conditioning }\end{array}$} \\
\hline & & $\begin{array}{c}\text { Chi- } \\
\text { Square }\end{array}$ & $\begin{array}{c}\operatorname{Pr}> \\
\text { ChiSq }\end{array}$ & $\begin{array}{c}\text { Chi- } \\
\text { Square }\end{array}$ & $\begin{array}{c}\mathrm{Pr}> \\
\text { ChiSq }\end{array}$ & $\begin{array}{l}\text { Chi- } \\
\text { Square }\end{array}$ & $\begin{array}{c}\operatorname{Pr}> \\
\text { ChiSq }\end{array}$ \\
\hline \multirow[t]{2}{*}{ Peppermint } & Neutral & 0.32 & 0.5745 & 4.35 & 0.037 & 2.76 & 0.0965 \\
\hline & Positive & 0.48 & 0.4883 & 18.54 & $<0.0001$ & 0.09 & 0.769 \\
\hline \multirow{2}{*}{ Lemon } & Neutral & 3.33 & 0.0679 & 8.47 & 0.0036 & 4.65 & 0.0311 \\
\hline & Positive & 1.43 & 0.2322 & 18.91 & $<0.0001$ & 0.64 & 0.4251 \\
\hline
\end{tabular}


Table 2 Values (t0), standard errors (SE), 95\% lower (lower) and upper (upper) confidence interval bound of the estimates of the mid-time oblivion of each type (strain) and each number of experiments (number exp.).

\begin{tabular}{|c|c|c|c|c|c|c|}
\hline & Strain & $\begin{array}{l}\text { Number of } \\
\text { experiences }\end{array}$ & to & $\mathrm{SE}$ & Lower & Upper \\
\hline \multirow{2}{*}{ Peppermint } & Uninfected & 1 & 23.8 & 1.4 & 21.0 & 26.7 \\
\hline & Infected & 1 & 18.9 & 2.4 & 14.0 & 23.8 \\
\hline \multirow{2}{*}{ Lemon } & Uninfected & 1 & 21.4 & 0.7 & 20.0 & 22.8 \\
\hline & Infected & 1 & 16.2 & 0.5 & 15.1 & 17.3 \\
\hline \multirow{2}{*}{ Peppermint } & Uninfected & 2 & 29.8 & 1.0 & 27.7 & 31.8 \\
\hline & Infected & 2 & 20.8 & 0.7 & 19.4 & 22.2 \\
\hline \multirow{2}{*}{ Lemon } & Uninfected & 2 & 28.9 & 0.7 & 27.4 & 30.4 \\
\hline & Infected & 2 & 20.7 & 1.1 & 18.4 & 23.0 \\
\hline \multirow{2}{*}{ Peppermint } & Uninfected & 3 & 42.5 & 2.9 & 36.8 & 48.2 \\
\hline & Infected & 3 & 27.1 & 0.6 & 25.9 & 28.4 \\
\hline \multirow{2}{*}{ Lemon } & Uninfected & 3 & 42.2 & 0.7 & 40.8 & 43.6 \\
\hline & Infected & 3 & 27.4 & 0.5 & 26.4 & 28.4 \\
\hline \multirow{2}{*}{ Peppermint } & Uninfected & 4 & 52.3 & 0.9 & 50.4 & 54.3 \\
\hline & Infected & 4 & 37.0 & 0.6 & 35.8 & 38.2 \\
\hline \multirow{2}{*}{ Lemon } & Uninfected & 4 & 51.6 & 0.8 & 49.9 & 53.2 \\
\hline & Infected & 4 & 36.1 & 0.4 & 35.2 & 36.9 \\
\hline \multirow{2}{*}{ Peppermint } & Uninfected & 5 & 57.8 & 0.9 & 56.0 & 59.7 \\
\hline & Infected & 5 & 40.2 & 1.2 & 37.8 & 42.7 \\
\hline \multirow{2}{*}{ Lemon } & Uninfected & 5 & 58.2 & 2.0 & 54.3 & 62.2 \\
\hline & Infected & 5 & 41.2 & 0.6 & 40.0 & 42.4 \\
\hline
\end{tabular}

